\title{
Patient attitudes towards change in adapted motivational interviewing for substance abuse: a systematic review
}

This article was published in the following Dove Press journal:

Substance Abuse and Rehabilitation

II July 2012

Number of times this article has been viewed

\author{
Samantha Ashley Wells ${ }^{1,2}$ \\ Tanya Smyth ${ }^{1,2}$ \\ Thomas G Brown $1,2,3$ \\ 'Department of Psychiatry, Douglas \\ Mental Health University Institute, \\ Montréal, Québec, Canada; \\ ${ }^{2}$ Department of Psychiatry, McGill \\ University, Montréal, Québec, Canada; \\ ${ }^{3}$ Foster Addiction Rehabilitation \\ Centre, St. Philippe de Laprairie, \\ Québec, Canada
}

\begin{abstract}
Adapted motivational interviewing (AMI) represents a category of effective, directive and client-centered psychosocial treatments for substance abuse. In AMI, patients' attitudes towards change are considered critical elements for treatment outcome as well as therapeutic targets for alteration. Despite being a major focus in AMI, the role of attitudes towards change in AMI's action has yet to be systematically reviewed in substance abuse research. A search of PsycINFO, PUBMED/MEDLINE, and Science Direct databases and a manual search of related article reference lists identified 416 published randomized controlled trials that evaluated AMI's impact on the reduction of alcohol and drug use. Of those, 54 met the initial inclusion criterion by evaluating AMI's impact on attitudes towards change and/or testing hypotheses about attitudes towards change as moderators or mediators of outcome. Finally, 19 studies met the methodological quality inclusion criterion based upon a Newcastle-Ottawa Quality Assessment Scale score $\geq 7$. Despite the conceptual importance of attitudes towards change in AMI, the empirical support for their role in AMI is inconclusive. Future research is warranted to investigate both the contextual factors (ie, population studied) as well as deployment characteristics of AMI (ie, counselor characteristics) likely responsible for equivocal findings.
\end{abstract}

Keywords: motivational interviewing, substance abuse, systematic review, readiness to change, self-efficacy

\section{Introduction}

Brief interventions are effective in reducing problematic alcohol consumption. ${ }^{1}$ One brief psychosocial intervention in particular, motivational interviewing (MI), has consistently shown its usefulness in decreasing problem drinking in diverse settings. ${ }^{2}$ MI is a directive, client-centered counseling style that expedites behavior change by guiding clients towards exploration and resolution of ambivalence concerning their problem behavior. ${ }^{3}$ At the core of MI practice is its "spirit," described by MI's authors as a way of "being" with people that contrasts with common, more didactic counseling styles emphasizing information exchange, client learning of skills, and clinicianselected behavioral change objectives. ${ }^{4}$ MI practitioners are encouraged to deploy a flexible repertoire of sophisticated tactics and an empathic communication style that respect client autonomy, self-efficacy, and client level of readiness.

As effective MI practice is contingent on the clinician's ability to tactically adapt (eg, "rolling with resistance") to the client rather than strictly adhere to a standardized intervention format, ${ }^{5-7}$ a "pure" form of MI is elusive. Pragmatic deployment of MI in the field and research involves a number of MI-inspired variants such as motivational enhancement therapy, brief motivational therapy, as well as other "motivational
Correspondence:Thomas G Brown Addiction Research Program, Research Centre of the Douglas Mental Health University Institute, 6875 Lasalle Blvd, Perry E-4II6,Verdun, Québec H4HIR3, Canada

Tel + I 5147616131 ext 3415

Email thomas.brown@mcgill.ca 
interventions" within which an MI component is embedded. ${ }^{8,9}$ Given the heterogeneity in MI's application, brief interventions that adhere to the spirit of MI have been referred to as "adapted motivational interviewing" (AMI). ${ }^{10,11}$ Though AMI has mainly been applied to alcohol use disorders, ${ }^{12}$ it has been found helpful in the treatment of other problem behaviors, such as risky drinking in drunk drivers, ${ }^{13}$ poor lifestyle management in Type 2 diabetes, ${ }^{14}$ asthma medication nonadherence, ${ }^{15}$ criminal re-offending, ${ }^{16}$ smoking, ${ }^{17}$ and obesity. ${ }^{18}$

Among evidence-based substance abuse treatments, AMI is distinctive by its almost exclusive focus on constituent elements of clients' attitudes towards change. As a significant factor in the outcome from any treatment, alteration in attitudes towards change represents a key therapeutic target. ${ }^{19}$ An attitude in this context can be defined as "the dynamic element in human behaviour, the motive for activity" ( $p$ 409). ${ }^{20}$ This concept can be operationalized to encompass clients' initial and dynamic appraisal of change, including positive, negative, or ambivalent reactions to change, interest, desire, and/or commitment to change, as well as acquisition of any related skill, proficiency, or belief involving self-efficacy and the consequences of change. Attitudes may interact with AMI as both a moderator and mediator of outcome, and thus constitute key proximal processes influencing how AMI works to reduce problem drinking. ${ }^{21}$ A moderator is a variable that affects the direction and/or strength of the relationship between an independent variable (eg, treatment exposure) and a dependent variable (eg, problem drinking). ${ }^{22} \mathrm{~A}$ mediator is a variable (eg, attitude towards change) altered by an independent variable that explains to a significant degree how an independent variable alters a dependent variable. ${ }^{22}$

\section{What are attitudes towards change?}

An influential conceptualization of attitudes towards change in substance abuse is rooted in the transtheoretical model of change (TMC) and a related construct, readiness to change (RTC).$^{23} \mathrm{Here}$, stage of change and RTC are proposed as ways for clinicians to understand how clients view their problem behavior and adapt their intervention approach accordingly. TMC proposes that individuals frequently experience up to six stages towards resolution of their substance abuse problem: (1) "precontemplation," limited recognition of the behavior posing a problem in relation to its advantages, and thus no perceived need to seek help; (2) "contemplation," ambivalence regarding substance abuse problems, weighing of pros and cons of changing behavior, but not yet prepared to change; (3) "preparation," initial steps towards change but without commitment to serious behavior change; (4) "action," active efforts to reduce or eliminate drinking; (5) "maintenance," active efforts to sustain behavioral change; and (6) "termination," resolution of the substance abuse problem in which little concern for relapse exists. ${ }^{24}$ A number of questionnaires have been developed to measure stage of change or RTC, including the Stage of Change Readiness and Treatment Eagerness Scale (SOCRATES), ${ }^{25}$ the Readiness to Change Questionnaire, ${ }^{26}$ the University of Rhode Island Change Assessment Scale (URICA), ${ }^{27}$ and the Readiness Ruler ${ }^{21}$ ( $\mathrm{see}^{28}$ for a review). Studies indicate that movement from "precontemplation" to "contemplation" and "action" results in more positive attitudes towards change ${ }^{29}$ as well as lower alcohol consumption. ${ }^{30}$

Like RTC, another attitude pertinent to AMI for substance abuse is self-efficacy. ${ }^{31,32}$ According to Bandura's Social Learning Theory, self-efficacy is the belief that one can successfully execute behaviors needed to produce a desired outcome. ${ }^{33}$ Self-efficacy has been shown to be a strong predictor of post-treatment drinking. ${ }^{34}$ Two facets of self-efficacy, expectancy to cope successfully with difficult and stressful situations and positive outcome expectation, ${ }^{30}$ have been positively associated with initiation of behavior change $^{35}$ and the probability of engaging in a behavior. ${ }^{34}$ Finally, other relevant attitudes towards change include attributions and perceptions of alcohol-related negative consequences, perceived drinking norms as well as personal engagement, initiation, adherence, and retention in substance abuse treatment.

Despite playing a central role in AMI, the role of attitudes towards change as either a moderator or mediator of outcome has yet to be systematically reviewed in substance abuse research. The present article describes the results of a systematic review of the AMI research literature regarding patient attitudes towards change. Specifically, the evidence in support of interactions between AMI and initial attitudes towards change in determining outcome and whether AMI positively changes these attitudes is summarized. Then, the evidence for presumptive support for AMI's role in altering client attitudes as a mediator of AMI's action is evaluated. A discussion of the findings' implications for practice and future research follows. Overall, the systematic review of this literature will contribute to both a better appreciation for how AMI works to achieve its benefits as well as further development and refinement of effective theory-based therapeutics. ${ }^{34}$ 


\section{Procedures}

\section{Literature search}

Three databases, PsycINFO, PUBMED/MEDLINE, and Science Direct, were searched using broad keywords such as "motivational interviewing + substance + attitude," "motivational interviewing + substance," "motivational interviewing + alcohol," "motivational interviewing + drugs," "motivational interviewing + attitudes to change," "motivational interviewing + self-efficacy," "motivational interviewing + readiness to change," "motivational enhancement therapy + attitude+substance," "motivational enhancement therapy + alcohol+attitude," "motivational enhancement therapy + drugs+attitude," "motivational enhancement therapy + attitudes to change," "motivational enhancement therapy + readiness to change," "motivational enhancement therapy + self-efficacy." Electronic searching was complemented by manual reference searches of the bibliographies of relevant articles using Google Scholar. The MI bibliography provided at the official Motivational Interviewing website (www.motivationalinterviewing.org) was also searched.

\section{Inclusion criteria}

Studies selected for this review had to meet the following inclusion criteria: (1) claim to deploy the principles of AMI in their experimental interventions; (2) include participants with an unresolved alcohol or illicit drug use problem; (3) be published or in press in the English language; (4) include an explicit statement about participant randomization in the abstract; (5) include a non-AMI comparison group, clearly described in the abstract; and (6) include an explicit statement pertaining to attitudes towards change in the abstract.

\section{Overview of study quality assessment}

The methodological quality of the selected studies was independently assessed by two reviewers (authors SW and TS) using an approach adapted from the Newcastle-Ottawa Quality Assessment Scale (NOS). ${ }^{36}$ Compared with other assessment protocols, the NOS is appropriate for reviews that involve a large number of studies due to its brevity, flexibility, simplicity, and reliability. ${ }^{37}$ The NOS scoring scale is a star rating system assessing methodology quality in three areas: participant selection (four items); comparability of exposed and nonexposed cohorts (two items); and assessment and adequacy of outcome measures (four items). Several amendments were made to the NOS to align it with the methodology and subject matter of relevant studies. Within the three areas of quality assessment, a maximum of one star can be given to each item in the selection and outcome categories, while

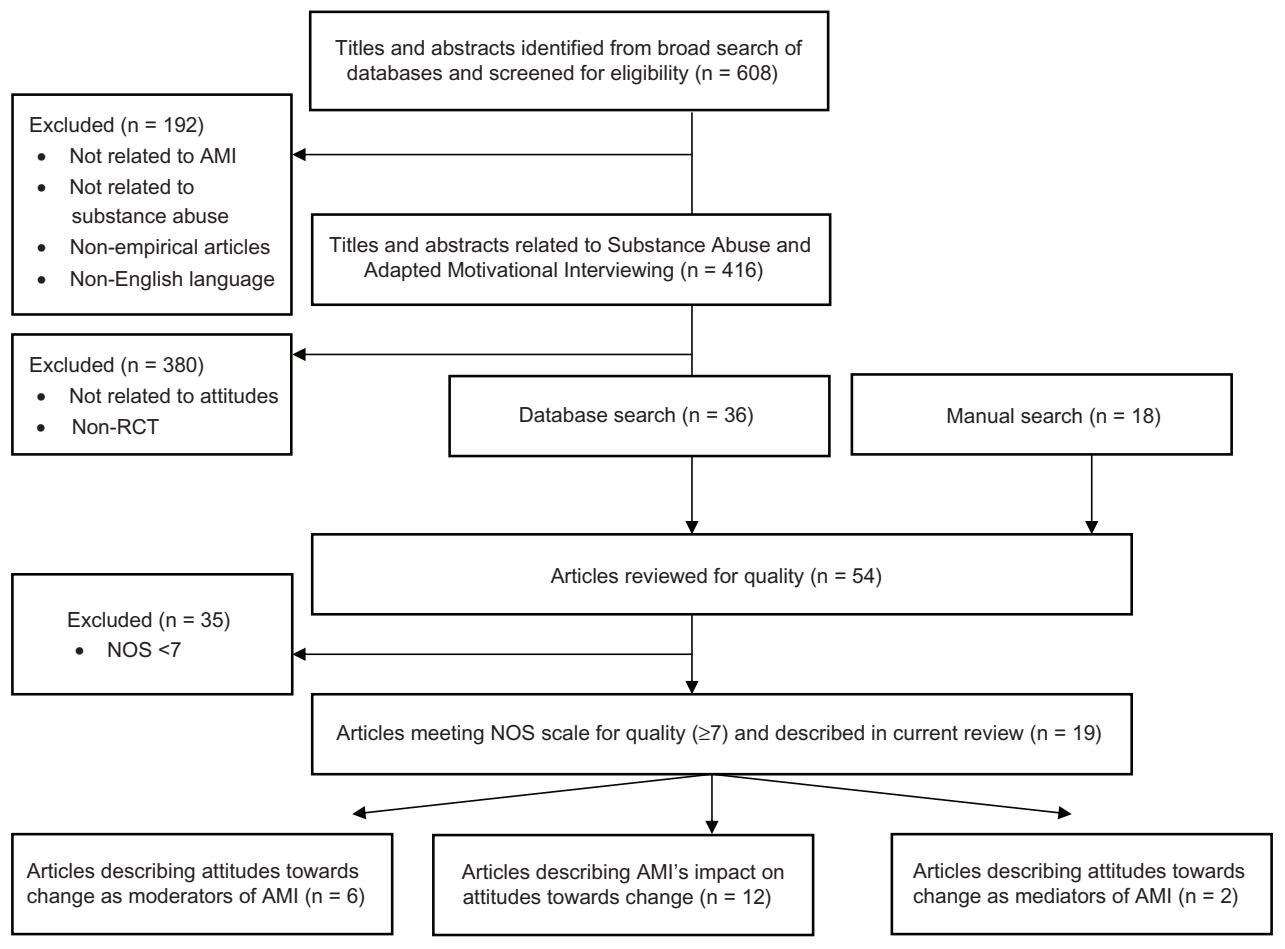

Figure I Flow chart depicting study inclusion.

Note: Some articles report multiple results and therefore appear in multiple categories.

Abbreviations: AMI, adapted motivational interviewing; NOS, Newcastle-Ottawa Quality Assessment Scale; RCT, randomized controlled trial. 
a maximum of two stars can be given to the comparability category. An overall score is then calculated, with a maximum possible score of nine indicating the highest quality. In the absence of an explicit convention for a designation of high quality, an overall NOS score cutoff of $\geq 7$ was chosen for inclusion in this review, a benchmark that has been used in another systematic review utilizing the NOS. ${ }^{38}$ Studies were rated based on the information reported in the relevant publication only. Any between-rater discrepancies on quality ratings were reviewed and reconciled. Figure 1 depicts the systematic application of inclusion and exclusion criteria to obtain pertinent studies for review. Table 1 details the NOS scores for each of the 54 articles meeting initial inclusion criteria. Nineteen randomized controlled trials met NOS quality criteria and were reviewed.

\section{Effect size calculations}

Effect sizes were calculated for significant results for descriptive purposes in cases where the authors present $t, F$, or $x^{2}$ statistics. Effect sizes were not calculated for mediation analyses or in cases where the authors did not provide the relevant statistics in their publication. Conventions used for effect sizes were those described by Cohen. ${ }^{90}$ The conversion formulas are described as follows. ${ }^{91,92}$

For $t$ statistics: $2 t /(d f)^{1 / 2}$

For $F\left(d f_{\text {numerator }}=1\right)$ statistics: $2\left(\mathrm{~F} / d f_{\text {denominator }}\right)^{1 / 2}$

For $x^{2}(d f=1)$ statistics: $2\left(x^{2} / \mathrm{N}-x^{2}\right)^{1 / 2}$

For $x^{2}(d f>1)$ statistics: $2\left(x^{2} / \mathrm{N}\right)^{1 / 2}$

\section{Results}

Tables 2-4 provide details of the 19 articles retained for review. The median overall NOS score of the evaluated studies was eight (53\% of studies). Six studies examined attitudes towards change as a moderator of the impact of AMI on substance abuse (Table 2), 12 studies investigated AMI's impact on attitudes toward changing substance abuse (Table 3), and two studies examined attitudes toward change as a mediator of the impact of AMI on substance abuse (Table 4). Some individual studies appear in multiple tables.

Of the included studies, eleven (58\%) used a selected group of participants (eg, pregnant substance abusers), and eight $(42 \%)$ had some discussion of the representativeness of the sample (eg, multisite recruitment). All studies recruited
Table I Newcastle-Ottawa Scale (NOS) quality assessment scoring for included studies

\begin{tabular}{|c|c|c|c|c|c|c|c|c|c|}
\hline \multirow[t]{2}{*}{ Article } & \multicolumn{9}{|c|}{ NOS overall score } \\
\hline & $\mathrm{I}$ & 2 & 3 & 4 & 5 & 6 & 7 & 8 & 9 \\
\hline Carroll $^{39}$ & & & $*$ & & & & & & \\
\hline Alemagno ${ }^{40}$ & & & & $*$ & & & & & \\
\hline Baker $^{41}$ & & & & $*$ & & & & & \\
\hline Dench $^{42}$ & & & & $*$ & & & & & \\
\hline Longshore $^{43}$ & & & & $*$ & & & & & \\
\hline $\mathrm{McKee}^{44}$ & & & & $*$ & & & & & \\
\hline Swanson ${ }^{45}$ & & & & $*$ & & & & & \\
\hline D'Amico ${ }^{46}$ & & & & & $*$ & & & & \\
\hline Davis ${ }^{47}$ & & & & & $*$ & & & & \\
\hline Carey $^{48}$ & & & & & $*$ & & & & \\
\hline LaChance $^{49}$ & & & & & $*$ & & & & \\
\hline Otiashvili ${ }^{50}$ & & & & & * & & & & \\
\hline Saunders ${ }^{51}$ & & & & & $*$ & & & & \\
\hline Bellack $^{52}$ & & & & & & $*$ & & & \\
\hline Booth $^{53}$ & & & & & & $*$ & & & \\
\hline Borsari $^{54}$ & & & & & & $*$ & & & \\
\hline Brown $^{55}$ & & & & & & $*$ & & & \\
\hline Carey $^{56}$ & & & & & & $*$ & & & \\
\hline Carroll $^{57}$ & & & & & & $*$ & & & \\
\hline Carroll158 & & & & & & $*$ & & & \\
\hline Freyer-Adam ${ }^{8}$ & & & & & & $*$ & & & \\
\hline Fromme 9 & & & & & & $*$ & & & \\
\hline Goti $^{59}$ & & & & & & $*$ & & & \\
\hline Ingersoll 60 & & & & & & $*$ & & & \\
\hline Kidorf $f^{61}$ & & & & & & $*$ & & & \\
\hline Maisto ${ }^{62}$ & & & & & & $*$ & & & \\
\hline Mason $^{63}$ & & & & & & $*$ & & & \\
\hline McCambridge ${ }^{64}$ & & & & & & $*$ & & & \\
\hline Montgomery ${ }^{65}$ & & & & & & * & & & \\
\hline Ondersma ${ }^{66}$ & & & & & & $*$ & & & \\
\hline Orford ${ }^{67}$ & & & & & & $*$ & & & \\
\hline Osterman ${ }^{68}$ & & & & & & $*$ & & & \\
\hline Robles $^{69}$ & & & & & & $*$ & & & \\
\hline Stein ${ }^{70}$ & & & & & & $*$ & & & \\
\hline Stotts ${ }^{71}$ & & & & & & $*$ & & & \\
\hline Ball $^{72}$ & & & & & & & $*$ & & \\
\hline Brown ${ }^{13}$ & & & & & & & $*$ & & \\
\hline Mastroleo $^{73}$ & & & & & & & $*$ & & \\
\hline Monti ${ }^{74}$ & & & & & & & $*$ & & \\
\hline Mullins ${ }^{75}$ & & & & & & & * & & \\
\hline Stein ${ }^{76}$ & & & & & & & $*$ & & \\
\hline Stein $^{77}$ & & & & & & & * & & \\
\hline Walters $^{78}$ & & & & & & & * & & \\
\hline Barrowclough $^{79}$ & & & & & & & & $*$ & \\
\hline Dennis $^{80}$ & & & & & & & & $*$ & \\
\hline Naar-King ${ }^{81}$ & & & & & & & & $*$ & \\
\hline Peterson ${ }^{82}$ & & & & & & & & * & \\
\hline Project $\mathrm{MATCH}^{83}$ & & & & & & & & * & \\
\hline Rohsenow ${ }^{84}$ & & & & & & & & * & \\
\hline Wain ${ }^{85}$ & & & & & & & & $*$ & \\
\hline Walker ${ }^{86}$ & & & & & & & & $*$ & \\
\hline Walton ${ }^{87}$ & & & & & & & & $*$ & \\
\hline Winhusen ${ }^{88}$ & & & & & & & & * & \\
\hline Project $\mathrm{MATCH}^{89}$ & & & & & & & & & $*$ \\
\hline
\end{tabular}




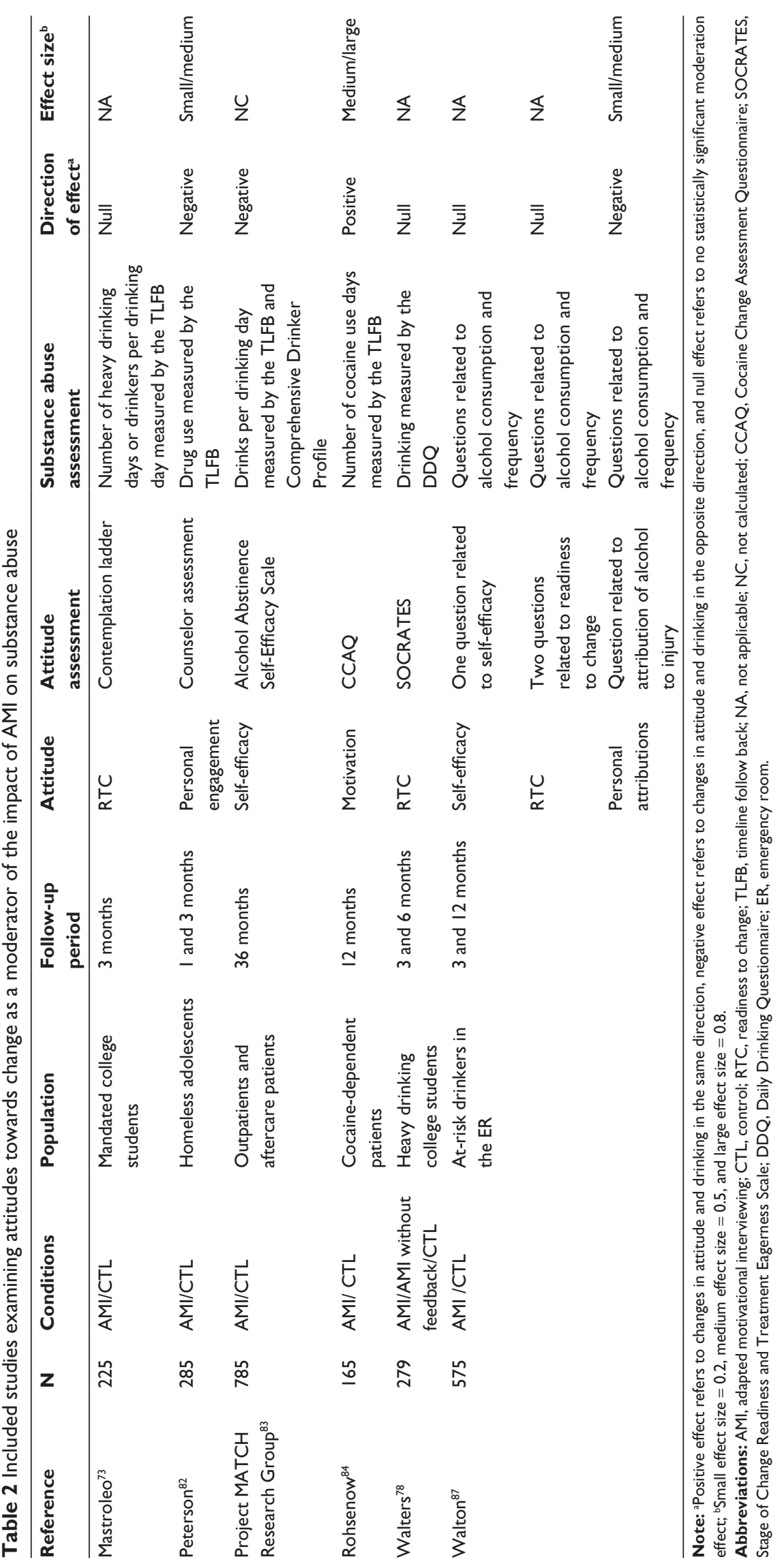




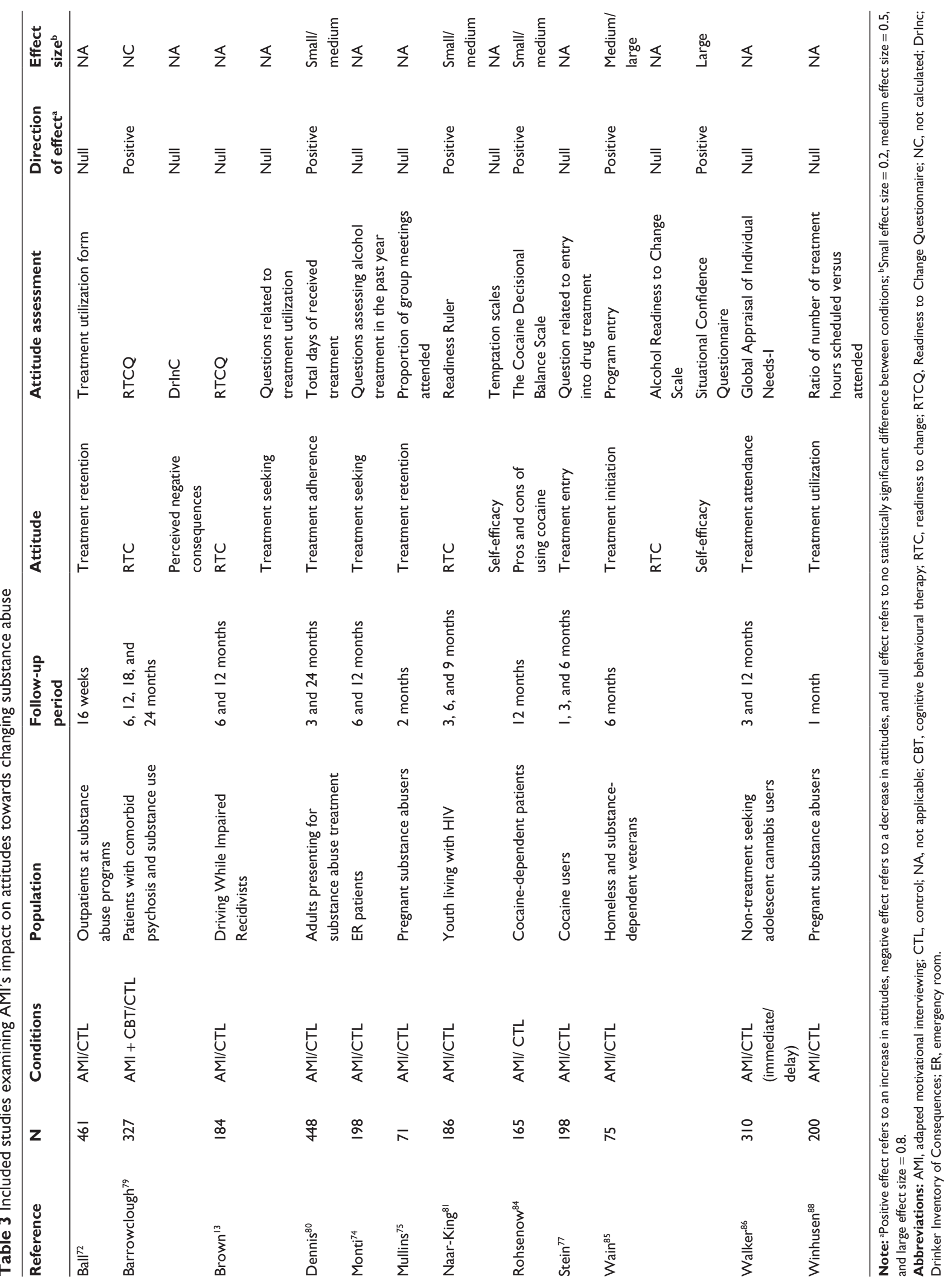


Table 4 Included studies examining attitudes towards change as a mediator of the impact of AMI on substance abuse

\begin{tabular}{|c|c|c|c|c|c|c|c|c|}
\hline Reference & $\mathbf{N}$ & Conditions & Population & $\begin{array}{l}\text { Follow-up } \\
\text { period }\end{array}$ & Attitude & Attitude assessment & $\begin{array}{l}\text { Substance abuse } \\
\text { assessment }\end{array}$ & $\begin{array}{l}\text { Directior } \\
\text { of effect }^{\mathrm{a}}\end{array}$ \\
\hline Stein $^{76, b}$ & 417 & $\begin{array}{l}\text { AMI/AMI + } \\
\text { booster/CTL }\end{array}$ & $\begin{array}{l}\text { Hazardous } \\
\text { drinkers in } \\
\text { the ER }\end{array}$ & $\begin{array}{l}\text { 3- and } \\
\text { I2-months }\end{array}$ & RTC & Contemplation Ladder & $\begin{array}{l}\text { Negative consequence } \\
\text { measured by the DrlnC }\end{array}$ & Negative \\
\hline Walters $^{78}$ & 279 & $\begin{array}{l}\text { AMI with feedback/ } \\
\text { AMI without } \\
\text { feedback/CTL }\end{array}$ & $\begin{array}{l}\text { Heavy drinking } \\
\text { college students }\end{array}$ & 6 months & $\begin{array}{l}\text { Norm } \\
\text { perceptions }\end{array}$ & $\begin{array}{l}\text { Questions related to } \\
\text { perceptions of US } \\
\text { college student drinking }\end{array}$ & $\begin{array}{l}\text { Drinking measured by } \\
\text { the DDQ }\end{array}$ & Positive \\
\hline
\end{tabular}

Notes: aPositive effect refers to changes in attitude and drinking in the same direction, and negative effect refers to changes in attitude and drinking in the opposite direction ${ }^{b}$ moderated mediation.

Abbreviations: AMI, adapted motivational interviewing; CTL, control; ER, emergency room; RTC, readiness to change; DrInC, Drinker Inventory of Consequences; DDQ, Daily Drinking Questionnaire.

their experimental and comparison group participants from a common source. Eighteen (95\%) studies incorporated an integrity check of the AMI intervention, which was most often a review of session audiotapes. Seventeen (89\%) of the studies controlled for potentially confounding factors in data analyses, and 16 (84\%) studies explicitly stated that blind assessment, treatment admission data, or biomarkers were used for outcome assessment. Fourteen (73.7\%) studies reported follow-up assessments of more than 6 months following baseline assessment, while five studies (26.3\%) reported a follow-up duration of less than 6 months. Overall, $15(68.4 \%)$ studies reported a participant attrition rate of less than $20 \%$, and two studies (10.5\%) claimed no attrition.

Based on qualitative observation, compared with included studies, excluded studies had higher attrition rates, and more frequently reported a follow-up participant rate of less than $80 \%$ and follow-up durations of less than 6 months. Nonselected studies less frequently reported blinding, control for confounding factors in the analysis, and checking for therapy fidelity.

\section{Do attitudes toward change moderate outcome from AMI?}

The studies reviewed for this section and the relevant results for attitudes towards change as a moderator of AMI are summarized in Table 2. Attitudes towards change that have been investigated as moderators of AMI outcome include RTC and motivation to change, self-efficacy, personal attributions of the negative consequences of alcohol, and personal engagement in treatment. Proponents of AMI have hypothesized that as an intervention that focuses on heightening motivation for change, it is particularly well suited for individuals with less motivation to change. ${ }^{3}$ Studies testing this hypothesis have yielded mixed results. In support, one study ${ }^{84}$ investigating motivation to change using the Cocaine Change Assessment
Questionnaire in 165 treated cocaine-dependent patients found that low motivation to change (pre-treatment "contemplation" scores higher than "action" scores) was associated with fewer cocaine-use days with AMI compared with high motivation to change. Three other studies, however, failed to find any evidence that RTC, as measured by the Contemplation Ladder, the SOCRATES, or independent questions related to RTC, moderated AMI's impact. ${ }^{73,78,87}$

Two studies investigated the moderating role of self-efficacy. One study ${ }^{83}$ supported the hypothesis that individuals higher in self-efficacy have better drinking outcomes in AMI compared with individuals lower in selfefficacy. The other, in a sample of 575 injured at-risk drinkers presenting in the emergency department,${ }^{87}$ found that selfefficacy measured by independent questions did not moderate AMI's impact on reducing substance abuse.

One study explored the moderating role of personal attributions concerning negative alcohol-related consequences. In a sample of injured at-risk drinkers presenting in the emergency department ${ }^{87}$ individuals who attributed their injury to alcohol consumption reported significantly less drinking at a 1-year follow up if they received AMI compared with individuals who also attributed their injury to alcohol but received the control condition. Lastly, with respect to counsellor assessment of participant engagement in treatment, one study ${ }^{82}$ found that homeless adolescents higher in treatment engagement had a significantly greater reduction in drug use than other homeless adolescents who were lower in treatment engagement.

Overall, based upon a review of well designed studies, moderation when detected was more likely to be in the direction predicted by proponents of AMI as opposed to the direction predicted by the TMC. Irrespective of the model used for prediction, however, the mixed findings on moderation fail to provide practical guidance in how to optimally 
assign patients to AMI treatments based upon initial attitudes towards change.

\section{Does AMI alter attitudes towards change?}

Studies of AMI as a way to change attitudes have evaluated its impact on RTC and motivation to change, self-efficacy, one's perceptions concerning negative consequences of continued use, the pros and cons of use, and attitudes towards treatment. The studies reviewed in this section and their relevant results are summarized in Table 3.

Four studies investigated AMI's role in altering RTC and motivation to change substance abuse. In a sample of 327 patients with comorbid psychosis and substance abuse, ${ }^{79}$ AMI increased RTC as measured by the Readiness to Change Questionnaire significantly more than a control procedure. In a sample of 186 youth living with HIV, AMI increased RTC measured by the Readiness Ruler significantly more than a control condition at a 3-month follow-up. ${ }^{81}$ Another study ${ }^{13}$ of a sample of 184 driving while impaired recidivists with substance abuse, however, detected no significant benefit with AMI compared with a control condition in increasing readiness using the Readiness to Change Questionnaire. Another study ${ }^{85}$ of homeless and substance-dependent veterans found no increase in RTC as measured by the Alcohol Readiness to Change Scale.

Two studies examined self-efficacy as an attitude that AMI aims to alter. One study of 75 homeless and substancedependent veterans ${ }^{85}$ found that compared with a control condition, AMI increased self-efficacy in dealing with situations linked to temptations to use as measured by the Situational Confidence Questionnaire at 6-month follow-up. Another study ${ }^{81}$ of youth living with HIV found no significant change in perceived self-efficacy with either AMI or a control condition.

Two studies examined whether AMI increased the perceived negative consequences of substance abuse or shifted the appraisal of the pros and cons of substance use. In a sample of patients with comorbid psychosis and substance abuse, AMI had no greater beneficial effect in altering perceptions of negative consequences of drinking as measured by the Drinker's Inventory of Consequences than a control condition. ${ }^{79}$ In cocaine-dependent patients at a 12-month follow-up, AMI was found to increase the perceived cons of cocaine use based upon the Cocaine Decisional Balance Scale significantly more compared with a control condition. ${ }^{84}$

Other studies have tested AMI's role in altering attitudes towards treatment, most notably ambivalence about change.
In this context, ambivalence was operationalized using indicators such as treatment retention, seeking, adherence, and utilization. Two of nine studies supported this notion. In a sample of 448 adults presenting for substance abuse treatment, AMI was found to have a more positive effect on increasing treatment adherence compared with a control condition. ${ }^{80}$ In a sample of 75 homeless and substancedependent veterans, individuals receiving AMI were more likely to start a substance abuse treatment program at 6-month follow-up compared with individuals receiving a control condition. ${ }^{85}$ AMI failed to positively alter other attitudes towards treatment in substance abuse treatment outpatients, ${ }^{72}$ cocaine users, ${ }^{77}$ driving while impaired recidivists, ${ }^{13}$ patients in the emergency room, ${ }^{74}$ pregnant substance abusers, ${ }^{75,88}$ and nontreatment seeking marijuanausing adolescents. ${ }^{86}$

In summary, with respect to RTC, motivation to change, self-efficacy, and the perceived consequences of substance abuse, both population and context appear to play a role in whether AMI selectively alters attitude change. For example, AMI increased RTC and motivation to change in individuals with comorbid psychiatric illness and HIV but not in homeless veterans or in individuals who drink and drive. It is possible that the psychological, neuropsychological, and emotional characteristics of individuals with concurrent medical or psychiatric illness or histories of significant trauma interact with exposure to AMI to influence attitude change. Lastly, there is sparse evidence to support the contention that AMI positively alters attitudes towards treatment.

\section{Do attitudes toward change mediate the impact of AMI?}

The studies reviewed for this section and their main results are summarized in Table 4. RTC and one's perceptions of normative drinking are two presumptive mediators that have been tested in the context of AMI and substance abuse outcomes. One study ${ }^{76}$ sought to specifically investigate RTC, measured by the Contemplation Ladder, as a mediator of AMI in hazardous drinkers presenting in emergency room settings. Participants were randomly assigned to one of three conditions; a standard care plus assessment, standard care plus assessment combined with AMI, or AMI combined with a later booster session. At 3-month follow-up, participants receiving AMI or AMI with a booster session who were high in initial RTC exhibited fewer alcohol-related negative consequences. In a moderated mediation model, treatment 
resulted in fewer alcohol-related negative consequences, in part because it enhanced and maintained RTC in these individuals.

Another study ${ }^{78}$ investigated whether AMI impacts substance abuse by modifying norm perceptions. Norm perception is operationalized as an individual's estimate of the percentage of their peers who drink more than they do, subtracted by the percentage of their peers who actually drink more based on national surveys. Using a randomized sample of 279 heavy-drinking college students, participants were assigned to one of four conditions: AMI with feedback, AMI without feedback, Web feedback only, and assessment only. The results revealed that a reduction in the discrepancy in norm perceptions mediated the effect of AMI with feedback in reducing drinking compared with the other study conditions.

In summary, the preliminary evidence indicates that, consistent with the TMC, AMI can act on RTC to positively alter substance abuse outcomes. Alteration of perceptions of normative drinking patterns also appears to be a mechanism for AMI's action. Unfortunately, too few studies have specifically explored AMI's presumptive mediators of outcome to make firm conclusions.

\section{Discussion}

To the authors' knowledge, this is the first systematic review in the field of AMI and substance abuse that focuses specifically on patient attitudes towards change. Despite the widely accepted notion placing attitudes to change at the center of AMI's effectiveness, surprisingly few high quality studies have specifically investigated this relationship. Pillars of AMI, such as RTC and motivation to change, have yielded mixed results as moderators of AMI's action or as key targets for alteration. RTC may, however, play a role as a mediator of AMI on substance abuse outcomes under certain conditions, at least based upon preliminary findings. Specific conclusions regarding the importance of other attitudes to AMI's action such as self-efficacy, the perceived negative consequences of substance use and the pros and cons of substance abuse are equivocal at best. The hypothesis that AMI plays a role in increasing positive attitudes towards treatment is largely unsupported.

Methodological factors may also underpin this incoherent picture. The marked diversity in the literature in the populations under investigation and the operationalization of key concepts are among the most likely factors contributing to discrepancies across studies. The importance of these factors in understanding the findings is deserving of further research. Moreover, quality assessment of all relevant articles and inclusion of only those studies meeting or surpassing a certain threshold, failed to neutralize discrepancies in the reporting practices seen between studies. For instance, effects sizes were impossible to derive based upon the information provided in some publications. As a result, comparative weighting of observed effects was compromised by the absence of this metric in many cases. Closer adherence to reporting conventions like the CONSORT statement ${ }^{93}$ would result in more balanced and comprehensive appraisals of studies in the area and allow firmer conclusions concerning the aggregate of their findings.

\section{Strengths and limitations}

Some methodological considerations from the current review are noteworthy. Inclusion of studies with high methodological quality significantly increases the validity of the findings. Furthermore, the specific inclusion and exclusion criteria adopted for the review increased the between-study comparability. The tradeoff of this strategy meant that a small number of studies focusing on "change talk," a putative mediator of AMI's effect, ${ }^{7}$ were excluded, given that such studies consisted primarily of secondary analyses of AMI audiotaped sessions, precluding comparisons to non-AMI conditions.

\section{Conclusion}

The role of attitudes towards change as moderators, targets of change, and mediators of AMI's effects remains uncertain. Promising strands of evidence suggest that attitudes towards change warrant ongoing attention in research of AMI for substance abuse. Future studies should focus on increasing the reliability of findings, either by using more robust study designs or adopting better reporting practices.

\section{Acknowledgments}

Authors Wells and Smyth receive salary support from a Canadian Institutes of Health Research Team Grant (SAF 94813). The first author receives additional funding from McGill's Department of Psychiatry Student Research Award 2012 as well as a graduate study fellowship from the Fonds de recherche en santé du Québec (FILE 23450). The authors would like to acknowledge the reviewers' contribution in improving an earlier version of the manuscript.

\section{Disclosure}

The authors report no conflicts of interest in relation to this work. 


\section{References}

1. Carey KB, Carey MP, Maisto SA, Henson JM. Brief motivational interventions for heavy college drinkers: a randomized controlled trial. J Consult Clin Psychol. 2006;74(5):943-954.

2. Vasilaki EI, Hosier SG, Cox WM. The efficacy of motivational interviewing as a brief intervention for excessive drinking: a meta-analytic review. Alcohol Alcohol. 2006;41(3):328-335.

3. Miller WR. Motivational interviewing with problem drinkers. Behav Psychother. 1983;11:147-172.

4. Rollnick S, Miller WR. What is motivational interviewing? Behav Cogn Psychother. 1995;23:325-334.

5. Amodeo M, Lundgren L, Cohen A, et al. Barriers to implementing evidence-based practices in addiction treatment programs: comparing staff reports on motivational interviewing, adolescent community reinforcement approach, assertive community treatment, and cognitivebehavioral therapy. Eval Program Plann. 2011;34(4):382-389.

6. Hettema J, Steele J, Miller WR. Motivational interviewing. Annu Rev Clin Psychol. 2005;1:91-111.

7. Miller WR, Rose GS. Toward a theory of motivational interviewing. Am Psychol. 2009;64(6):527-537.

8. Freyer-Adam J, Coder B, Baumeister SE, et al. Brief alcohol intervention for general hospital inpatients: a randomized controlled trial. Drug Alcohol Depend. 2008;93(3):233-243.

9. Fromme K, Corbin W. Prevention of heavy drinking and associated negative consequences among mandated and voluntary college students. J Consult Clin Psychol. 2004;72(6):1038-1049.

10. Burke BL, Arkowitz H, Menchola M. The efficacy of motivational interviewing: A meta-analysis of controlled clinical trials. J Consult Clin Psychol. 2003;71(5):843-861.

11. Patterson DA. Motivational interviewing: does it increase clients' retention in intensive outpatient treatment? Subst Abus. 2008;29(1):17-23.

12. Larimer ME, Cronce JM. Identification, prevention and treatment: a review of individual-focused strategies to reduce problematic alcohol consumption by college students. J Stud Alcohol Suppl. 2002(14):148-163.

13. Brown TG, Dongier M, Ouimet MC, et al. Brief motivational interviewing for DWI recidivists who abuse alcohol and are not participating in DWI intervention: a randomized controlled trial. Alcohol Clin Exp Res. 2010;34(2):292-301.

14. Rubak S, Sandbaek A, Lauritzen T, Borch-Johnsen K, Christensen B. General practitioners trained in motivational interviewing can positively affect the attitude to behaviour change in people with type 2 diabetes. One year follow-up of an RCT, ADDITION Denmark. Scand J Prim Health Care. 2009;27(3):172-179.

15. Schmaling KB, Blume AW, Afari N. A randomized controlled pilot study of motivational interviewing to change attitudes about adherence to medications for asthma. J Clin Psychol Med Settings. 2001;8(3):167-172.

16. McMurran M. Motivational interviewing with offenders: a systematic review. Leg Criminol Psychol. 2009;14:83-100.

17. Soria R, Legido A, Escolano C, Lopez Yeste A, Montoya J. A randomised controlled trial of motivational interviewing for smoking cessation. Br J Gen Pract. 2006;56(531):768-774.

18. Van Dorsten B. The use of motivational interviewing in weight loss. Curr Diabetes Report. 2007;7(5):386-390.

19. Cooney NL, Babor TF, DiClemente CC, Del Boca FK. Clinical and Scientific Implications of Project MATCH. Vol 222-237. Cambridge: Cambridge University Press; 2003.

20. North CC. Social Problems and Social Planning. New York: McGrawHill; 1932.

21. Heather N, Smailes D, Cassidy P. Development of a Readiness Ruler for use with alcohol brief interventions. Drug Alcohol Depend. 2008;98(3):235-240.

22. Baron RM, Kenny DA. The moderator-mediator variable distinction in social psychological research: conceptual, strategic, and statistical considerations. J Pers Soc Psychol. 1986;51(6):1173-1182.
23. Prochaska J, DiClemente C. Toward a Comprehensive Model of Change. New York, NY: Plenum Press; 1986.

24. Connors GJ, Donovan DM, DiClemente C. Substance Abuse Treatment and the Stages of Change. New York: Guilford Press; 2001.

25. Miller WR, Tonigan JS. Assessing drinkers' motivation for change: the Stages of Change and Treatment Eagerness Scale (SOCRATES). Psychol Addict Behav. 1996;10:81-89.

26. Rollnick S, Heather N, Gold R, Hall W. Development of a short 'readiness to change' questionnaire for use in brief, opportunistic interventions among excessive drinkers. Br J Addict. 1992;87(5):743-754.

27. McConnaughy E, DiClemente C, Prochaska J, Velicer W. Stages of change in psychotherapy: a follow-up report. Psychotherapy. 1989; 26:494-503.

28. Carey K, Purmine D, Maisto SA, Carey M. Assessing readiness to change substance abuse. Clin Psychol Sci Pract. 1999;6:245-266.

29. Hile MG, Adkins RE. The impact of substance abusers' readiness to change on psychological and behavioral functioning. Addict Behav. 1998;23(3):365-370.

30. Rollnick S, Morgan M, Heather N. The development of a brief scale to measure outcome expectations of reduced consumption among excessive drinkers. Addict Behav. 1996;21(3):377-387.

31. Faris AS, Cavell TA, Fishburne JW, Britton PC. Examining motivational interviewing from a client agency perspective. J Clin Psychol. 2009;65(9):955-970.

32. Kadden RM, Litt MD. The role of self-efficacy in the treatment of substance use disorders. Addict Behav. 2011;36(12):1120-1126.

33. Bandura A. Self-efficacy: toward a unifying theory of behavioral change. Psychol Rev. 1977;84(2):191-215.

34. DiClemente C. Mechanisms, determinants and processes of change in the modification of drinking behavior. Alcohol Clin Exp Res. 2007;31(10 Suppl): $13 \mathrm{~s}-20 \mathrm{~s}$.

35. Demmel R, Beck B, Richter D, Reker T. Readiness to change in a clinical sample of problem drinkers: relation to alcohol use, self-efficacy, and treatment outcome. Eur Addict Res. 2004;10(3):133-138.

36. Stang A. Critical evaluation of the Newcastle-Ottawa scale for the assessment of the quality of nonrandomized studies in meta-analyses. Eur J Epidemiol. 2010;25(9):603-605.

37. Hootman JM, Driban JB, Sitler MR, Harris KP, Cattano NM. Reliability and validity of three quality rating instruments for systematic reviews of observational studies. Res Synth Methods. 2011;2:110-118.

38. Leonardi-Bee J, Pritchard D, Britton J. Asthma and current intestinal parasite infection: systematic review and meta-analysis. Am J Respir Crit Care Med. 2006;174(5):514-523.

39. Carroll KM, Libby B, Sheehan J, Hyland N. Motivational interviewing to enhance treatment initiation in substance abusers: an effectiveness study. Am J Addict. 2001;10(4):335-339.

40. Alemagno SA, Stephens RC, Stephens P, Shaffer-King P, White P. Brief motivational intervention to reduce HIV risk and to increase HIV testing among offenders under community supervision. J Correct Health Care. 2009;15(3):210-221.

41. Baker A, Lewin T, Reichler H, et al. Motivational interviewing among psychiatric in-patients with substance use disorders. Acta Psychiatr Scand. 2002;106(3):233-240.

42. Dench S, Bennett G. The impact of brief motivational intervention at the start of an outpatient day programme for alcohol dependence. Behav Cogn Psychother. 2000;28(02):121-130.

43. Longshore D, Grills C, Annon K. Effects of a culturally congruent intervention on cognitive factors related to drug-use recovery. Subst Use Misuse. 1999;34(9):1223-1241.

44. McKee SA, Carroll KM, Sinha R, et al. Enhancing brief cognitivebehavioral therapy with motivational enhancement techniques in cocaine users. Drug Alcohol Depend. 2007;91(1):97-101.

45. Swanson AJ, Pantalon MV, Cohen KR. Motivational interviewing and treatment adherence among psychiatric and dually diagnosed patients. J Nerv Ment Dis. 1999;187(10):630-635. 
46. D’Amico EJ, Miles JN, Stern SA, Meredith LS. Brief motivational interviewing for teens at risk of substance use consequences: a randomized pilot study in a primary care clinic. J Subst Abuse Treat. 2008;35(1):53-61.

47. Davis TM, Baer JS, Saxon AJ, Kivlahan DR. Brief motivational feedback improves post-incarceration treatment contact among veterans with substance use disorders. Drug Alcohol Depend. 2003;69(2): 197-203.

48. Carey KB, Henson JM, Carey MP, Maisto SA. Which heavy drinking college students benefit from a brief motivational intervention? J Consult Clin Psychol. 2007;75(4):663-669.

49. LaChance H, Feldstein Ewing SW, Bryan AD, Hutchison KE. What makes group MET work? A randomized controlled trial of college student drinkers in mandated alcohol diversion. Psychol Addict Behav. 2009;23(4):598-612.

50. Otiashvili D, Kirtadze I, O'Grady KE, Jones HE. Drug use and HIV risk outcomes in opioid-injecting men in the Republic of Georgia: behavioral treatment+naltrexone compared to usual care. Drug Alcohol Depend 2012;120(1-3):14-21.

51. Saunders B, Wilkinson C, Phillips M. The impact of a brief motivational intervention with opiate users attending a methadone programme. Addiction. 1995;90(3):415-424.

52. Bellack AS, Bennett ME, Gearon JS, Brown CH, Yang Y. A randomized clinical trial of a new behavioral treatment for drug abuse in people with severe and persistent mental illness. Arch Gen Psychiatry. 2006;63(4):426-432.

53. Booth RE, Corsi KF, Mikulich-Gilbertson SK. Factors associated with methadone maintenance treatment retention among streetrecruited injection drug users. Drug Alcohol Depend. 2004;74(2): 177-185.

54. Borsari B, Carey KB. Effects of a brief motivational intervention with college student drinkers. J Consult Clin Psychol. 2000;68(4): 728-733.

55. Brown TG, Dongier M, Ouimet MC, et al. The role of demographic characteristics and readiness to change in 12-month outcome from two distinct brief interventions for impaired drivers. J Subst Abuse Treat. 2012;42(4):383-391.

56. Carey KB, Henson JM, Carey MP, Maisto SA. Perceived norms mediate effects of a brief motivational intervention for sanctioned college drinkers. Clin Psychol (New York). 2010;17(1):58-71.

57. Carroll KM, Ball SA, Nich $\mathrm{C}$, et al. Motivational interviewing to improve treatment engagement and outcome in individuals seeking treatment for substance abuse: a multisite effectiveness study. Drug Alcohol Depend. 2006;81(3):301-312.

58. Carroll KM, Martino S, Ball SA, et al. A multisite randomized effectiveness trial of motivational enhancement therapy for Spanish-speaking substance users. J Consult Clin Psychol. 2009;77(5):993-999.

59. Goti J, Diaz R, Serrano L, et al. Brief intervention in substance-use among adolescent psychiatric patients: a randomized controlled trial. Eur Child Adolesc Psychiatry. 2010;19(6):503-511.

60. Ingersoll KS, Farrell-Carnahan L, Cohen-Filipic J, et al. A pilot randomized clinical trial of two medication adherence and drug use interventions for HIV+ crack cocaine users. Drug Alcohol Depend. 2011;116(1-3):177-187.

61. Kidorf M, Disney E, King V, Kolodner K, Beilenson P, Brooner RK Challenges in motivating treatment enrollment in community syringe exchange participants. J Urban Health. 2005;82(3):456-467.

62. Maisto SA, Conigliaro J, McNeil M, Kraemer K, Conigliaro RL, Kelley ME. Effects of two types of brief intervention and readiness to change on alcohol use in hazardous drinkers. J Stud Alcohol. 2001;62(5):605-614

63. Mason M, Pate P, Drapkin M, Sozinho K. Motivational interviewing integrated with social network counseling for female adolescents: a randomized pilot study in urban primary care. J Subst Abuse Treat. 2011;41(2):148-155.
64. McCambridge J, Strang J. The efficacy of single-session motivational interviewing in reducing drug consumption and perceptions of drugrelated risk and harm among young people: results from a multi-site cluster randomized trial. Addiction. 2004;99(1):39-52.

65. Montgomery L, Burlew AK, Kosinski AS, Forcehimes AA. Motivational enhancement therapy for African American substance users: a randomized clinical trial. Cultur Divers Ethnic Minor Psychol. 2011;17(4):357-365.

66. Ondersma SJ, Winhusen T, Erickson SJ, Stine SM, Wang Y. Motivation enhancement therapy with pregnant substance-abusing women: does baseline motivation moderate efficacy? Drug Alcohol Depend. 2009;101(1-2):74-79.

67. Orford J, Hodgson R, Copello A, Wilton S, Slegg G. To what factors do clients attribute change? Content analysis of follow-up interviews with clients of the UK Alcohol Treatment Trial. J Subst Abuse Treat. 2009;36(1):49-58

68. Osterman RL, Dyehouse J. Effects of a motivational interviewing intervention to decrease prenatal alcohol use. West J Nurs Res. 2012;34(4):434-454.

69. Robles RR, Reyes JC, Colon HM, et al. Effects of combined counseling and case management to reduce HIV risk behaviors among Hispanic drug injectors in Puerto Rico: a randomized controlled study. J Subst Abuse Treat. 2004;27(2):145-152.

70. Stein LA, Monti PM, Colby SM, et al. Enhancing substance abuse treatment engagement in incarcerated adolescents. Psychol Serv. 2006;3(1):25-34.

71. Stotts AL, Schmitz JM, Rhoades HM, Grabowski J. Motivational interviewing with cocaine-dependent patients: a pilot study. J Consult Clin Psychol. 2001;69(5):858-862.

72. Ball SA, Martino S, Nich C, et al. Site matters: multisite randomized trial of motivational enhancement therapy in community drug abuse clinics. J Consult Clin Psychol. 2007;75(4):556-567.

73. Mastroleo NR, Murphy JG, Colby SM, Monti PM, Barnett NP. Incident-specific and individual-level moderators of brief intervention effects with mandated college students. Psychol Addict Behav. 2011;25(4):616-624.

74. Monti PM, Barnett NP, Colby SM, et al. Motivational interviewing versus feedback only in emergency care for young adult problem drinking. Addiction. 2007;102(8):1234-1243.

75. Mullins SM, Suarez M, Ondersma SJ, Page MC. The impact of motivational interviewing on substance abuse treatment retention: a randomized control trial of women involved with child welfare. J Subst Abuse Treat. 2004;27(1):51-58.

76. Stein LA, Minugh PA, Longabaugh R, et al. Readiness to change as a mediator of the effect of a brief motivational intervention on posttreatment alcohol-related consequences of injured emergency department hazardous drinkers. Psychol Addict Behav. 2009;23(2): 185-195.

77. Stein MD, Herman DS, Anderson BJ. A motivational intervention trial to reduce cocaine use. J Subst Abuse Treat. 2009;36(1):118-125.

78. Walters ST, Vader AM, Harris TR, Field CA, Jouriles EN. Dismantling motivational interviewing and feedback for college drinkers: a randomized clinical trial. J Consult Clin Psychol. 2009;77(1):64-73.

79. Barrowclough $\mathrm{C}$, Haddock $\mathrm{G}$, Wykes $\mathrm{T}$, et al. Integrated motivational interviewing and cognitive behavioural therapy for people with psychosis and comorbid substance misuse: randomised controlled trial. BMJ. 2010;341:c6325.

80. Dennis M, Scott CK, Funk R. An experimental evaluation of recovery management checkups (RMC) for people with chronic substance use disorders. Eval Program Plann. 2003;26(3):339-352.

81. Naar-King S, Parsons JT, Murphy D, Kolmodin K, Harris DR. A multisite randomized trial of a motivational intervention targeting multiple risks in youth living with HIV: initial effects on motivation, self-efficacy, and depression. J Adolesc Health. 2010;46(5): $422-428$. 
82. Peterson PL, Baer JS, Wells EA, Ginzler JA, Garrett SB. Shortterm effects of a brief motivational intervention to reduce alcohol and drug risk among homeless adolescents. Psychol Addict Behav. 2006;20(3):254-264.

83. Project MATCH Research Group. Matching alcoholism treatments to client heterogeneity: Project MATCH three-year drinking outcomes. Alcohol Clin Exp Res. 1998;22(6):1300-1311.

84. Rohsenow DJ, Monti PM, Martin RA, et al. Motivational enhancement and coping skills training for cocaine abusers: effects on substance use outcomes. Addiction. 2004;99(7):862-874.

85. Wain RM, Wilbourne PL, Harris KW, et al. Motivational interview improves treatment entry in homeless veterans. Drug Alcohol Depend. 2011;115(1-2):113-119.

86. Walker DD, Stephens R, Roffman R, et al. Randomized controlled trial of motivational enhancement therapy with nontreatment-seeking adolescent cannabis users: a further test of the teen marijuana check-up. Psychol Addict Behav. 2011;25(3):474-484.

87. Walton MA, Goldstein AL, Chermack ST, et al. Brief alcohol intervention in the emergency department: moderators of effectiveness. J Stud Alcohol Drugs. 2008;69(4):550-560.
88. Winhusen T, Kropp F, Babcock D, et al. Motivational enhancement therapy to improve treatment utilization and outcome in pregnant substance users. J Subst Abuse Treat. 2008;35(2):161-173.

89. Project MATCH Research Group. Matching alcoholism treatments to client heterogeneity: Project MATCH posttreatment drinking outcomes. J Stud Alcohol. 1996;58(1):7-29.

90. Cohen JJ. Statistical Power Analysis for the Behavioral Sciences. 2nd ed. New Jersey: Erlbaum;1988.

91. Friedman H. Simplified determinations of statistical power, magnitude of effect and research sample sizes. Educ Psychol Meas. 1982;42:521-526.

92. Wolf FM. Meta Analysis: quantitative methods for research synthesis. Beverly Hills, CA: Sage; 1986

93. Schulz KF, Altman DG, Moher D, Group C. CONSORT 2010 statement: updated guidelines for reporting parallel group randomised trials. BMJ. 2010;340:c332.
Substance Abuse and Rehabilitation

\section{Publish your work in this journal}

Substance Abuse and Rehabilitation is an international, peer-reviewed, open access journal publishing original research, case reports, editorials, reviews and commentaries on all areas of addiction and substance abuse and options for treatment and rehabilitation. The manuscript management system is completely online and includes a very quick and fair

\section{Dovepress}

peer-review system. Visit http://www.dovepress.com/testimonials.php to read real quotes from published authors. 